\title{
Behaviour of cable-stayed bridge's girder to multi-support excitation
}

\author{
Masrilayanti ${ }^{1 *}$, Aryanti Riza ${ }^{1}$, Kurniawan Ruddy $^{1}$, and Siregar Zakpar ${ }^{1}$ \\ ${ }^{1}$ Department of Civil Engineering, Universitas Andalas, Padang, Indonesia
}

\begin{abstract}
This paper describes the behaviour of the longitudinal and cross girder of cable-stayed bridge due to multi-support excitation. Cablestayed bridges should be analysed by different support accelerations since generally they have long spans. In this research, an $800 \mathrm{~m}$ long cablestayed bridge was assessed by giving different support accelerations. The method used is by arranging simulation using structural analysis software. The displacement time histories are obtained by converting the response spectra using MathCAD. The structural responses were then compared to the application of single support excitation. Results show that there is a significant discrepancy between the two analyses. Single support excitation causes lower responses if the ground motion magnitudes are similar to the small magnitude of the multi-support excitation, and it yields to a higher responses if the magnitudes are similar to the greater value of the multi-support excitation.
\end{abstract}

\section{Introduction}

The development of bridges construction technology has been very fast and fascinating. This is because of the vast increase in computer technology, science, material, and other structural analysis and design methods. To date, many types of bridges have been built around the world by variation in length, spans, construction methodology and height. The longest span bridge built to date is Danyang-Kunshan Grand Bridge, China, with a length of about $185 \mathrm{~km}$. This bridge has been included in the longest bridges in the world and holds the Guinness World Record. The type of this bridge is a suspension bridge, which uses cable as the main part of its structure.

Another type of cable supported bridge is cable-stayed bridges. These kinds of bridges are relatively more attractive and commonly represent a more precious engineering achievement, although the span is relatively shorter compared to suspension bridges. However, it is admitted that cable-stayed bridges which have more than three spans are usually more complicated. Generally, the length of cable-stayed bridges is up to around 1 $\mathrm{km}$. To date, the longest span of any cable-stayed bridge is the Russky Bridge over the

\footnotetext{
${ }^{*}$ Corresponding author: masrilayanti@gmail.com
} 
Bosphorus in Vladivostok, Russia, followed by Sutong Yantze Bridge in China. Table 1 below shows the five longest cable-stayed bridges recorded in the world.

Table 1. The 5 longest cable-stayed bridges span.

\begin{tabular}{|c|l|c|c|c|c|}
\hline Rank & \multicolumn{1}{|c|}{ Name } & $\begin{array}{c}\text { Span } \\
(\mathbf{m})\end{array}$ & $\begin{array}{c}\text { Number } \\
\text { of pylons }\end{array}$ & $\begin{array}{c}\text { Year of } \\
\text { completion }\end{array}$ & Country \\
\hline 1 & Russky Bridge & 1140 & 2 & 2012 & Russia \\
\hline 2 & $\begin{array}{l}\text { Sutong Yangtze River } \\
\text { Bridge }\end{array}$ & 1088 & 2 & 2008 & China \\
\hline 3 & Stonecutters Bridge & 1018 & 2 & 2009 & China \\
\hline 4 & $\begin{array}{l}\text { Edong Yangtze River } \\
\text { Bridge }\end{array}$ & 926 & 2 & 2010 & China \\
\hline 5 & Tatara Bridge & 890 & 2 & 1999 & Japan \\
\hline
\end{tabular}

Since the trend of cable supported bridge structures is for long-span bridges, the effect of dynamic loadings should be the main consideration, since the longer the span, the more dangerous the structure due to dynamic loadings. Therefore, more research should be conducted to study the problems related to overcoming the potential disaster of the structures.

This research is based on the urgency of studies of long-span structural behaviors due to earthquake loads, especially in real condition. The longer the spans, the more it can have multi-support acceleration on their supports. This is because the condition of the soils is possible to be different, also the distance from the earthquake source or epicenter will be different as well.

The research aims to evaluate the response structures due to asymmetric ground acceleration, especially to the girders of an $800 \mathrm{~m}$ cable-stayed bridge. The response structures assessed are the displacements and dynamic moments of the girders.

\section{Previous research}

Since an earthquake excitation consists of the superposition of a large number of waves with different characteristics, seismic ground motions at the supports can vary significantly along a cable-stayed bridge span. The variations in the support motions can significantly influence the internal forces generated in the structure. So, in calculating the seismic response of suspension bridges, the assumption of uniform ground motion at the supports of this extended structures cannot be considered valid.

In previous studies, analyses of bridges to multiple-support or spatially varying seismic ground motions were performed by various researchers. Masrilayanti [1] stated that multisupport excitation gives effect even to a stiff bridge, such as an integral bridge. Alexander [2] concluded that seismically induced forces could be accrued if identical support excitation (ISE) analysis is used in place of a multi-support excitation (MSE) analysis. He studied the effects of multi-support excitation by using real multi-station data from SMART-1 in Taiwan. Adanur et al. [3] stated in their research that, for multi-support excitation, the structural responses for each random vibration analysis depend largely on the intensity and frequency contents of power spectral density functions. In their research, the spatial variability of ground motions between the support points is taken into account 
with a coherency function that characterizes the incoherence, wave-passage and siteresponse effects.

Karmakar et al. [4] found that in using spatially variable motions the response in some locations on the bridge girder may be under-predicted, even if the motion with maximum intensity is uniformly applied at all supports. Meanwhile, Su et al. [5] also researched the behavior of the steel trussed arch to multi-support excitations. The spatial variation of ground motion was modeled by an empirical coherency loss function. Numerical results indicate that horizontal multi-support excitations have a quite large amplification effect on the seismic responses of the trussed arch. This amplification effect cannot be ignored in the seismic design of such structures.

Papadopoulus and Sextos [6] researched the effect of asynchronous earthquake ground motion on the transverse response of base-isolated bridges. They concluded that there is clear evidence that the local increase of seismic demand in the bridge studied was associated with the excitation of the first anti-symmetric mode of vibration.

\subsection{Single support excitation}

Rajasekaran [7] states that vibration can occur in a structure by imposing initial conditions, which generally manifest themselves as the energy input. If the initial input is imparting velocity to the system, kinetic energy is produced. If the displacement is imparted to the system, potential energy is produced.

Modeling of input quantities, such as ground motions and gravity loads, is a critical step in the earthquake response analysis of structures. The number of time histories is specified in seismic design standards for dynamic analysis, usually three to seven records in each principal direction of structural response.

In a single support excitation system, it is assumed that all of the structure's parts have a uniform movement due to ground displacement as a fixed base. Therefore, it is acceptable for short spans systems because the movement of the structure will not affect the reaction of the internal structure.

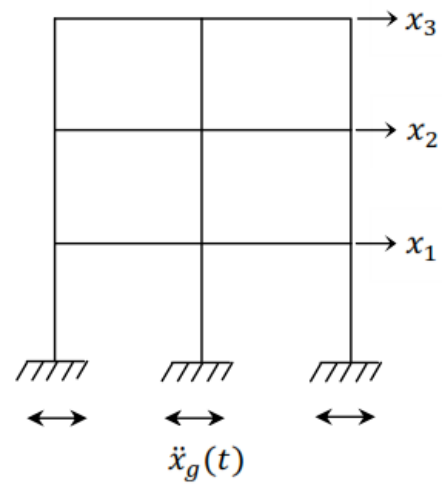

Fig. 1. Single support excitation.

As can be seen from Fig. 1, the ground acceleration applied to the support of the structure are the same, in magnitude and direction. This should yield the structure to deform in a relatively predictable direction.

\subsection{Multi-support excitation}

Multi-support excitation is a condition when asymmetric accelerations are applied to the support of the structure. This can occur when the structure has a long span, and/ or has 
different conditions of the soil types. Thus, the forces induced by the earthquake or the source of vibration will vary depending on the distance from the source or the type of the soil condition. Bridges which have long spans, or dams with a large length, usually should be designed by using multi-support excitation. An illustration of the multi-support excitation can be seen from Fig. 2.

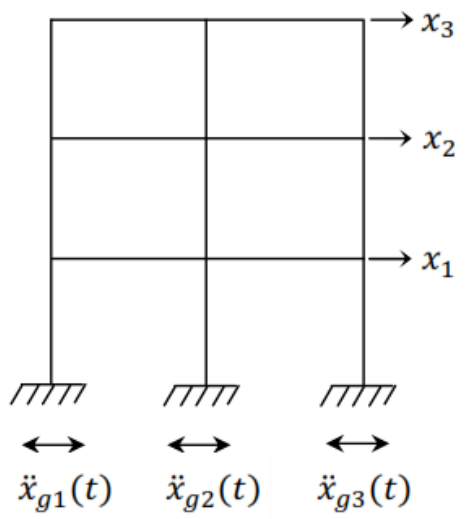

Fig. 2. Multi support excitation.

The equation for multi-support excitation as defined by Chopra [8] is as follows:

$$
\left.\left(\begin{array}{ll}
\text { Mss } & \text { Msg } \\
\text { Mgs } & \text { Mgg }
\end{array}\right\}\left\{\begin{array}{l}
\ddot{x}^{\mathrm{t}} \\
\ddot{\mathrm{x}} g
\end{array}\right\}+\left(\begin{array}{cc}
\text { Css } & \text { Csg } \\
\text { Cgs } & \text { Cgg }
\end{array}\right\}\left\{\begin{array}{c}
\dot{\mathrm{x}}^{\mathrm{t}} \\
\dot{\mathrm{x}} g
\end{array}\right\}+\left\{\begin{array}{c}
\text { Kss } \\
\text { Kgs }
\end{array}\right\} \begin{array}{cc}
\text { Ksg } & x^{\mathrm{t}} \\
\text { Kgg } & x g
\end{array}\right\}=\left\{\begin{array}{c}
0 \\
P g
\end{array}\right\}
$$

Notation $s$ and $g$ in the items refer to the structure and the ground, respectively. $M$ is defined as the mass of the structure, $C$ is damping coefficient, $K$ is stiffness, whereas $\ddot{\mathrm{X}}^{\mathrm{t}}$ is acceleration, $\dot{\mathrm{x}}^{\mathrm{t}}$ is velocity, and $x^{\mathrm{t}}$ is displacement of the structure. $\ddot{\mathrm{x}} g$ is the acceleration of the ground, $\dot{\mathrm{x}} g$ is the velocity of the ground, and $x g$ is the displacement of the ground, and $P g$ is the ground force. All of the terms are presented in matrices.

\subsection{Earthquake mapping information system}

Fortunately, due to the rapid increase in technology, it is easy nowadays to find useful and trusted data to be used in the earthquake and dynamic analysis. For example, earthquake data can be easily found from trusted sources. Indonesia also has a website which provides useful information regarding earthquake information. From website www.pusjatan.go.id or www.puskim.go.id, the condition of earthquake zonation or response spectrum for each area in Indonesia can be observed. Thus, the response spectrum of different types of soil can be obtained.

\subsection{Cable-stayed bridges as long span bridges}

Cable-stayed bridges are known as an attractive and powerful bridge for long spans. They use cables to support the traffic loads and distribute the loads to the pylon and girders. Compared to suspension bridges, cable-stayed bridges are relatively more aesthetic and stronger in overcoming dynamic loads such as earthquakes and wind loads. There are three main structures in this type of bridges, namely: cables structure, girders, and pylons. The loads distribute from deck to girders, cables, pylons, and finally reach to the foundation. 


\section{Research methodology}

The research methodology of this study is by simulating the earthquake loads using SAP2000. An $800 \mathrm{~m}$ span length of the cable-stayed bridge is analyzed to obtain the structural response of the bridge after applying different kinds of displacement stories.

Displacement time histories are conducted by doubled integration of the transient acceleration which was obtained previously by processing with a Seismosoft. Thus, the reactions of the structure, especially the girder, are then observed.

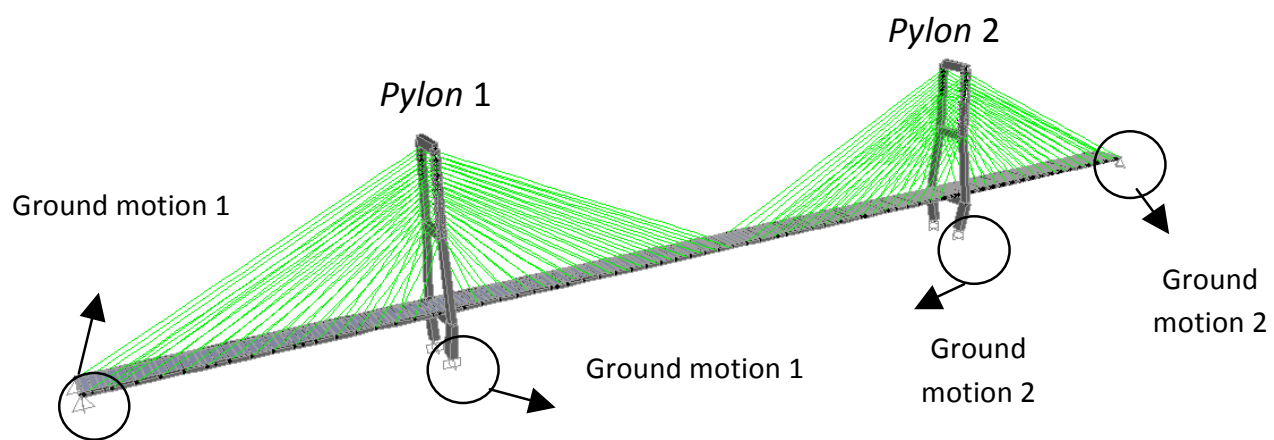

Fig. 3. Bridge modelling of cable-stayed for multi-support excitation using SAP2000.

Fig. 3 shows the modeling of the bridge and the two different ground motions applied to the support of the bridge. The motions are applied in a longitudinal direction. Ground motion 1 is applied to the two pairs of left supports, and ground motion 2 is loaded to the two pairs of right supports. This case is known as MSE. SSE 1 is when all four pairs of supports have the same ground motion, that is ground motion 1, while SSE is when all supports have ground motion 2. Fig. 4 describes the configuration of ground motion 1 and 2 .

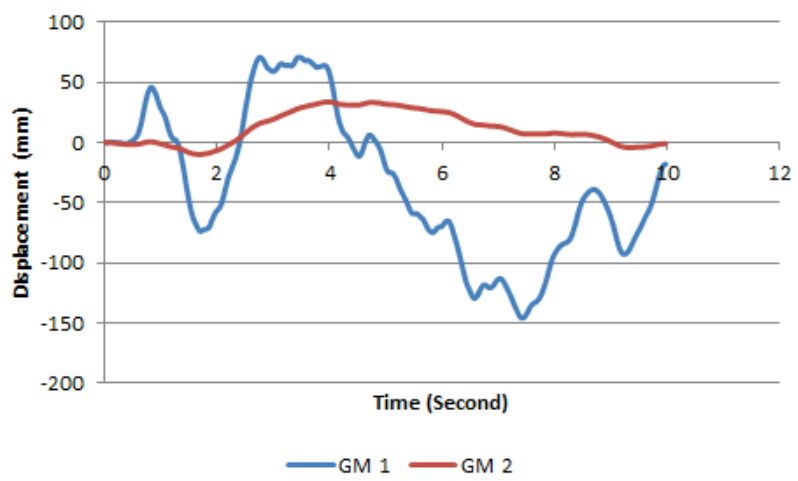

Fig. 4. Comparison of both GM (ground motion) applied to the bridge model.

\section{Results and discussion}

From the results of the research, it can be seen that there is a big discrepancy between the two analyses. Fig. 5 below shows the multi-support excitation yield to a larger displacement compared to self-weight and SSE 2, however, it has less displacement compared to SSE 1. 


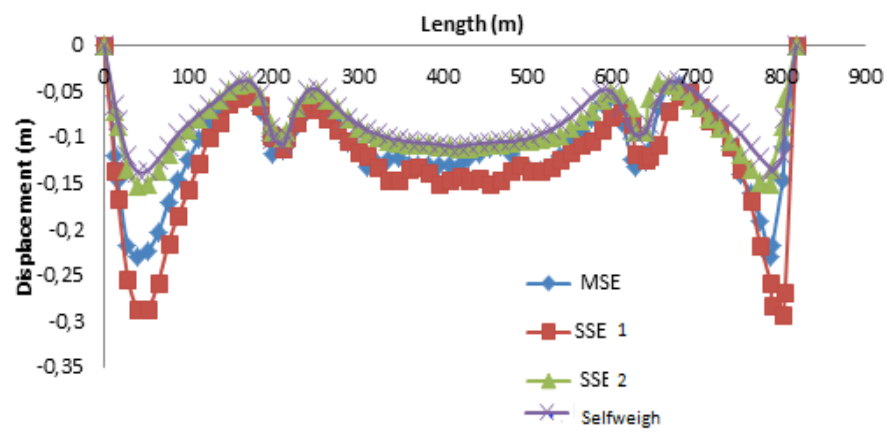

Fig. 5. Comparison of girder displacements due to MSE, SSE and selfweight.

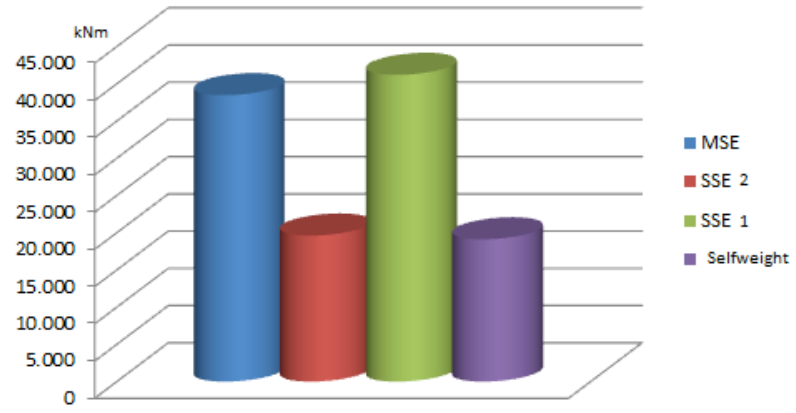

Fig. 6. Comparison of maximum moment due to MSE, SSE and selfweight.

Fig. 6 describes the discrepancy among the moments of the models. It can be seen from the figure that the results are compatible with the maximum moments, since MSE has larger moments compared to self-weight and SSE 2, yet has a lower result compared to SSE 1 .

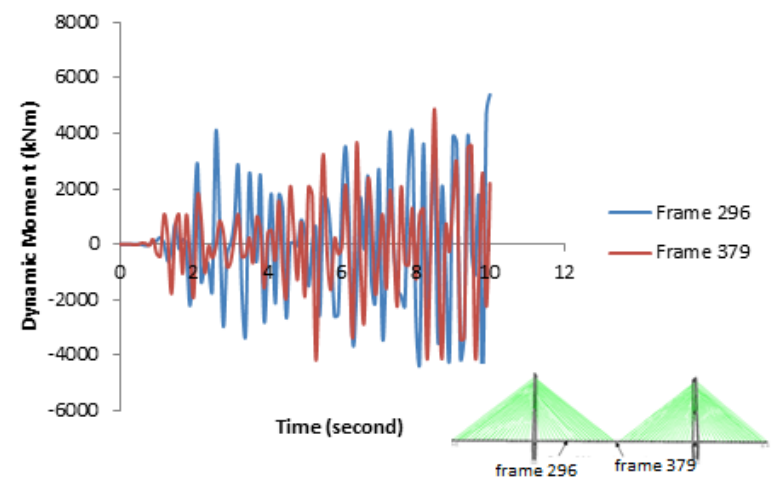

Fig. 7. Comparison of dynamic moments of two different points due to MSE.

Comparing the two different places for multi-support excitation, as can be seen from Fig. 7, it can be seen that the dynamic moments resulted are relatively different. Dynamic moments in the middle of the span are larger compared to the side spans. This result is compatible with the static analysis which also has the maximum value in the middle of the span. 


\section{Conclusions}

In conclusion, it can be stated that multi-support excitation yields a larger analysis result compared to a lower single support excitation. Applying the lower acceleration earthquake loads uniformly to all supports of the structure will be resulting to lower internal forces and displacements of the structures. On the other hand, when the higher acceleration loads are applied uniformly to the supports, the analysis then comes to higher results rather than multi support excitation. Therefore, in designing a super long span bridge, it is recommended to do it in multi support excitation method because it can be an intermediary between the lowest and the highest acceleration earthquake loads which are applied uniformly. In other words, the multi support excitation should be considered to make reliable seismic analysis and to conduct reliable structural analysis and evaluation to super long span bridges. This study has strengthened the conclusions which has been found by other researchers by using different bridge cases and methods.

\section{References}

1. M. Masrilayanti, L. Weekes, Proc. of the Sixth Int. IABMAS Conf. 2012 (2012)

2. N.A. Alexander, Computers \& Structures 86, 1 (2008)

3. S. Adanur, A.C. Altunisik, K. Soyluk, A. Bayraktar, A.A. Dumanoglu, Case Studies in Structural Eng. 5 (2016)

4. D. Karmakar, S. Ray-Chaudhuri, M. Shinozuka, Soil Dyn. and Earthq. Eng. 42 (2012)

5. L. Su, S. Dong, S. Kato, J. of Construction and Steel Res. 63, 6 (2007)

6. S.P. Papadopoulos, A.G. Sextos, Soil Dynamics and Earthquake Eng. 113 (2018)

7. S. Rajasekaran, Structural dynamics of earthquake engineering: Theory and application using Mathematics and Matlab (CRC Press, Florida, 2009)

8. A.K. Chopra, Dynamics of structures: Theory and applications to earthquake engineering (Pearson/Prentice Hall, New Jersey, 2007) 